\title{
Diaphragmatic hernia revealed by post-partum respiratory distress
}

\author{
Alexandre Descloux*, Ulrich Schneider, Thomas Kocher \\ Department of Surgery, Kantonsspital Baden, Im Ergel 1, 5404 Baden, Switzerland
}

Email address:

alexandre.descloux@ksb.ch (A. Descloux)

\section{To cite this article:}

Alexandre Descloux, Ulrich Schneider, Thomas Kocher. Diaphragmatic Hernia Revealed by Post-Partum Respiratory Distress. International Journal of Surgery. Vol. 1, No. 5, 2013, pp. 70-72. doi: 10.11648/j.js.20130105.12

\begin{abstract}
Introduction: Diaphragmatic hernias occurring during pregnancy or during labor are very rare. This kind of injury or complication is mostly diagnosed with delay. Case report: A 30-year-old, primigravida woman presented an acute respiratory distress three weeks after childbirth by emergency caesarian section. The past history was uneventful till a car crash three years ago with whiplash injury without blunt abdominal trauma. The diagnostic of the dyspnea was assured by thorax CT scan. Symptoms of gastrointestinal obstruction were not recorded. An emergency thoracotomy was performed. The incarcerated gastric fundus had to be resected. The central diaphragmatic hernia could be closed by sutures. An abdominal approach was not necessary. The postoperative follow-up was uncomplicated. Discussion and Conclusion: Incarceration of abdominal viscera by diaphragmatic hernia is an uncommon cause of pleural empyema. Her happening during pregnancy or during the peri-partum period is increasingly rarely and represents a life-threatening event for the pregnant woman and her fetus. Early diagnosis and surgery in an emergency setting are required. Diagnose and treatment of diaphragmatic hernias in women in child-bearing age should happen before pregnancy in matter to avoid potential lethal complications for the expectant mother as well as for the fetus.
\end{abstract}

Keywords: Diaphragmatic Hernia, Pregnancy, Surgery

\section{Introduction}

Diaphragmatic hernias are classified in congenital and acquired. Congenital hernias are mostly localized in the recessus lumbocostalis (95\%), called Bochdalek hernia, and more rarely in the recessus sternocostalis $(5 \%)$, on the left side called Larrey hernia and on the right side called Morgagni hernia. Acquired hernias are due to an elevated intraabdominal pressure, connective tissue weakness and traumatas. The commonest form of diaphragmatic hernia is the axial hiatal hernia (90\%). $25 \%$ of fifty-year-old persons are afflicted, but only $10 \%$ develop symptoms. By the seventy-year-old population, the incidence increases over $60 \%$, of which only one third have complaints [1]. Traumatic hernias are rare, a herniation of abdominal viscera in the thorax more infrequent. Polytrauma patients are more affected. The left side of the diaphragm is more vulnerable.

Diaphragmatic hernias occurring during pregnancy or during labor are very rare. This kind of complication is mostly diagnosed with delay. Once discovered, emergency surgery is required to protect mother and child.

\section{Case Report}

A 30-year-old, primigravida woman presented pneumonia three weeks after childbirth by emergency caesarean section. The diagnostic of pleural empyema was assured by chest X-ray followed by CT scan (Fig. 1).

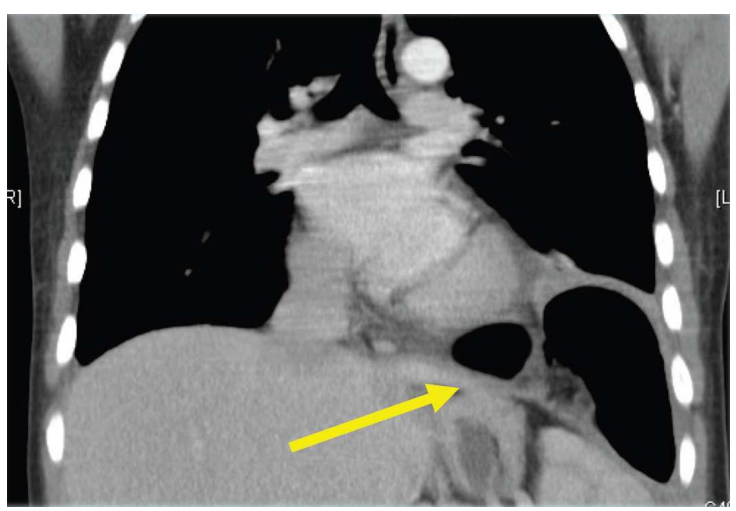

Figure 1. Preoperative chest CT scan, coronar view: hernia opening (arrow) 
Pus has been evacuated by insertion of a thoracic drain. At this point, the patient has been transferred to us. We indicated surgery as defined by early decortication and performed a posterolateral thoracotomy approach. The pleural peel was decorticated. Diagnose of diaphragmatic hernia came unexpected during surgery. The incarcerated and perforated gastric fundus had to be resected (Fig. 2).

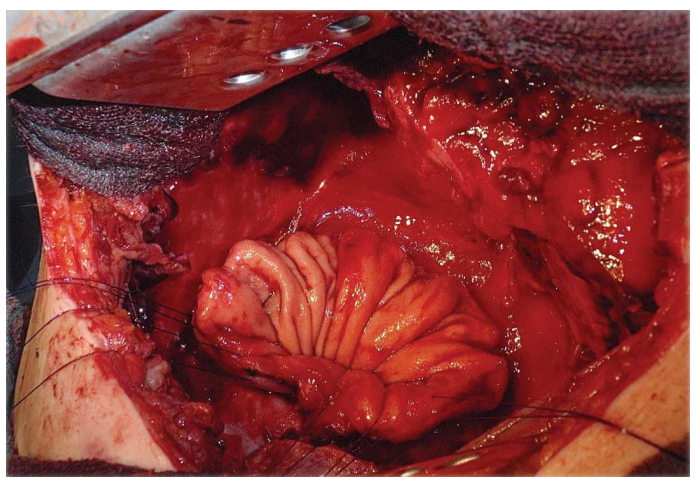

Figure 2. Intraoperative view: situs after gastric fundus resection

The central diaphragmatic hernia could be closed by sutures (Fig. 3). An additive abdominal approach was not necessary. The postoperative course was uncomplicated (Fig. 4).

Symptoms of gastrointestinal obstruction before surgery were not recorded. Retrospectively, the hernia was visible in the preoperative CT scan. The past history was uneventful till a car crash three years ago with whiplash injury without blunt abdominal trauma.

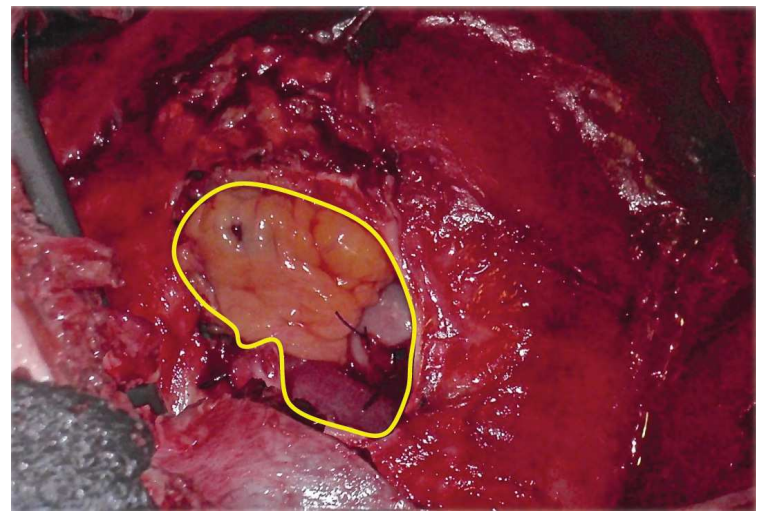

Figure 3. Intraoperative view: hernia opening (circle)

\section{Discussion}

Traumatic diaphragmatic ruptures have to be repaired in emergency setting. Suture of the diaphragmatic opening with non absorbable material is sufficient enough. If the lesion stays unrecognized, surgery would be performed with some delaying. Mesh reinforcement must be reserved in selected cases with biggest defects.

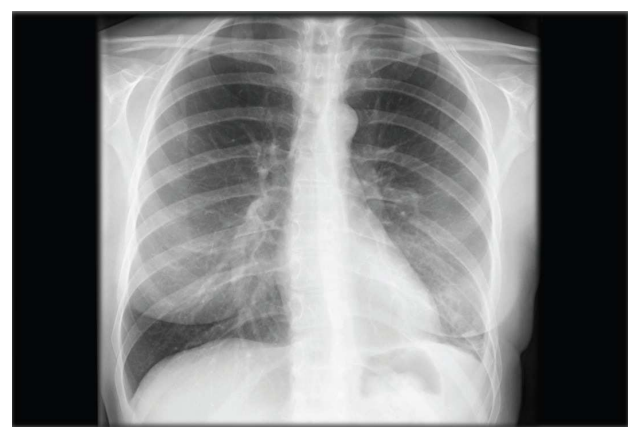

Figure 4. Postoperative chest X-ray

As written before, diaphragmatic rupture during pregnancy or labor is very rare but represents a life-threatening condition for mother and/or child. Once the injury diagnosed, immediate treatment, requiring surgery, is indicated. Only few case reports of diaphragmatic hernias during the peri-partum period are documented [2-8]. A review of the literature, conducted 2006 by Eglinton et al. [5], compiled a modest number of 37 cases. During the following years, a lot of reports were published.

Some reports are presenting similar conditions but not strictly the same. As example, Lococo et al. [9] reported an unusual case of complicated hiatal hernia with intrathoracal gastric perforation months after childbirth, so a preexisting hiatal hernia increasing in growth during pregnancy and becoming symptomatic in the post-partum period. Complaints by hiatal hernia are usually exacerbating during the course of pregnancy. Nausea and vomiting are common symptoms of pregnancy but only $1 \%$ of expectant mothers are suffering from hyperemesis gravidarum. This condition appears typically during the first two trimenons. Ruptures during this period with rapid increase in the uterine size are documented [10]. If it happens during pregnancy, the mortality of mother and fetus is really higher as after childbirth $[11,12]$. Thereby it would be judicious to diagnose and to treat diaphragmatic hernias in women in child-bearing age before pregnancy in matter to avoid potential lethal complications for the expectant mother and her fetus.

\section{Conclusion}

Incarceration of abdominal viscera by diaphragmatic hernia is an uncommon cause of pleural empyema. Her happening during pregnancy or during the peri-partum period is increasingly rarely and represents a life-threatening event for the pregnant woman and her fetus. Early diagnosis and surgery in an emergency setting are required.

\section{References}

[1] Decker D, Decker P (2011) Zwerchfellhernien. Allgemeinund Viszeralchirurgie up2date, Vol. 2:111-130. doi: $10.1055 / \mathrm{s}-0030-1270971$ 
[2] Dessolle L, Vibert E, Bernabé C, Chitrit Y, Saint-Léger S (2004) Syndrome occlusif chez une femme enceinte révélant une hernie diaphragmatique post-traumatique méconnue. J Gynecol Obstet Biol Reprod 33:441-443

[3] Desurmont S, Tariel D, Magnin G, Pierre F (2005) Hernie diaphragmatique maternelle pendant la grossesse: A propos de 2 cas. J Gynecol Obstet Biol Reprod 34(cahier1):711-715

[4] Dietrich CL, Smith CE (2001) Anesthesia for cesarean delivery in a patient with an undiagnosed traumatic diaphragmatic hernia. Anesthesiology 95(4):1028-1031

[5] Eglinton TW, Coulter GN, Bagshaw PF, Cross LA (2006) Diaphragmatic hernias complicating pregnancy. ANZ J Surg 76:553-557

[6] Hammoudi D, Bouderka MA, Benissa N, Harti A (2004) Diaphragmatic rupture during labor. Int $\mathrm{J}$ Obstet Anesth $13: 284-286$

[7] Rifki Jai S, Bensardi F, Hizaz A, Chehab F, Khaiz D, Bouzidi D (2007) A late post-traumatic diaphragmatic hernia revealed during pregnancy by post-partum respiratory distress. Arch Gynecol Obstet (2007) 276:295-298. doi: $10.1007 / \mathrm{s} 00404-007-0347-\mathrm{z}$
[8] Williams M, Appelboam R, McQuillan P (2003) Presentation of diaphragmatic herniae during pregnancy and labour. Int $\mathrm{J}$ Obstet Anesth 12:130-134

[9] Lococo F, Cesario A, Meacci E, Granone P (2012) Intrathoracic gastric perforation: a late complication of an unknown postpartum recurrent hiatal hernia. Interact CardioVasc Thorac Surg 2012;15:317-319

[10] Schwentner L, Wulff C, Kreienberg R, Herr D (2011) Exacerbation of a maternal hiatus hernia in early pregnancy presenting with symptoms of hyperemesis gravidarum: case report and review of the literature. Arch Gynecol Obstet. 2011 Mar;283(3):409-14. doi: 10.1007/s00404-010-1719-3

[11] Chen X, Yang X, Cheng W (2007) Diaphragmatic tear in pregnancy induced by intractable vomiting: a case report and review of the literature. J Matern Fetal Neonatal Med. 2012 Sep;25(9):1822-4. doi:10.3109/14767058.2011.640371

[12] Morcillo-Lopez I, Hidalgo-Mora JJ, Baamonde A, Diaz-Garcia C (2010) Gastric and diaphragmatic rupture in early pregnancy. Interact Thorac CardioVasc Surg 2010;11:713-715 